MICHAEL L. WACHTER

University of Pennsylvania

\title{
Intermediate Swings in Labor-Force Participation
}

MACROECONOMETRIC analysis of labor-force participation rates has concentrated on quarterly variations of these rates and their relationship with the short-run business cycle. Cyclical changes in unemployment rates are assumed to cause changes in participation rates as workers become discouraged in their search and drop out of the labor force; while longerrun effects tend to be subsumed in a general trend variable or variables.

I shall argue that the omission from the analysis of variables that reflect intermediate swings in labor-force participation rates arising from demographic factors lends an unwarranted significance to short-run cyclical factors and the time trend. These demographic variables provide the key to the main puzzle in the behavior of participation rates over the postwar period-that is, the tendency for participation rates of younger and older women to grow rapidly at different points in time. For example, in a seminal demographic study in 1968, Richard A. Easterlin wrote that "the most challenging recent observation calling for explanation is the remarkable rise in the rates of older women" (emphasis added). ${ }^{1}$ According to

Note: My research in this area has been supported at various times by the $\mathrm{Na}$ tional Science Foundation, the National Institute of Child Health and Human Development, and the General Electric Foundation. I am grateful to Choongsoo Kim for extensive research assistance and to Dennis Ahlburg and Debbie Faigen for computational help. Some unpublished data used in the paper were made available through the assistance of Gordon Green of the U.S. Bureau of the Census and Paul O. Flaim of the U.S. Department of Labor. I also wish to thank Richard A. Easterlin and Susan M. Wachter for helpful comments on this draft.

1. Richard A. Easterlin, Population, Labor Force, and Long Swings in Economic Growth: The American Experience (Columbia University Press for the National Bureau of Economic Research, 1968), p. 165. 
the more recent data, the story has been reversed. The participation rates of females 45 and over, after rising strongly between 1948 and 1963, have risen marginally since then. For young women, a flat trajectory of participation rates prior to 1960 has been replaced by a steeply rising trend since then. The payoff now is in explaining this latter development and the reversal of the age groups with dynamic growth in participation.

The notion that the recent sharp increase in participation rates of younger females can be "explained" by trend variables may convey the impression that the economic experience of this cohort has otherwise been similar to that of older cohorts. This, however, is not the case. Indeed, the groups with the strongest upward trends of late are the cohorts born in the baby boom of the late 1940s and early 1950s.

My hypothesis is that the main explanation of changes in the participation rates of women involves these changes in the age structure of the population and associated relative-income effects, factors that fluctuate with an intermediate rather than a short frequency. The line of causality runs as follows: The entrance of the baby-boom cohort into the labor market swelled the supply of young workers; that in turn led to a steep relative decline in wages and living standards for young people; and that adversity led to the drop in fertility rates and spurred the rise in participation of younger women. This model is hereafter denoted the relative-income model.

In this model, workers have a desired or anticipated standard of living, $W^{*}$, that is formed by the past experience of their own cohort plus the contemporaneous conditions facing other age cohorts. When their own current income, $W$, is low relative to $W^{*}$, additional workers, especially second wage earners in the family, enter the labor market in order to help achieve the desired standard. Since the end of World War II, fluctuations in the relative income of a cohort have been inversely related to changes in that cohort's relative size in the population structure.

The recent increase in participation rates of younger women is thus not a spontaneous event associated with a newfound freedom. Rather, it is largely a result of their being part of an unprecedentedly large cohort, which has experienced a marked decline in relative earnings. In an attempt to alleviate this misfortune, younger women have been flooding into the labor market.

These same factors also help explain the participation behavior of older females. For example, the recent slowdown in the growth of their partici- 
pation rates is due to the replacement of the cohort that first entered the labor market during the Great Depression by the mothers of the baby boom. Thus, the current cohort of older workers is a relatively small group that has experienced, throughout its life cycle, relatively high family income that could be maintained without two wage earners.

The participation rates of women have been rising steadily since the turn of the century. There may well be a long-run trend in these rates based on sociological factors, or even some recent increase in such a trend. The argument offered here is that there are important variations around such a trend that are associated largely with intermediate swings in demographic events.

To explore these matters, this paper is organized along the following lines: The first section discusses the justification of the discouragedworker model, the prevailing model of participation behavior in the literature. The second section introduces the relative-income model and the age structure of the population as an intermediate-swings variable. The third section presents the empirical tests of the intermediate-swings equations. The fourth section focuses on the implications that the various equations have for the discouraged-worker effect. The final section utilizes the alternative specifications to forecast changes in participation rates.

\section{The Discouraged-Worker Model}

It is generally considered that participation rates are significantly and negatively related to short-run cyclical swings in the unemployment rate. ${ }^{2}$ As unemployment increases, some potential workers become discouraged and drop out of the labor force; that is,

$$
L F P R_{i}=f\left(U, T_{i}, L F P R_{t-1, i}\right), f_{U}<0,
$$

2. For the most recent treatment, see George L. Perry, "Potential Output and Productivity," $B P E A, 1: 1977$, pp. 11-47. For an early treatment of the discouragedworker model, see Alfred Tella, "The Relation of Labor Force to Employment," Industrial and Labor Relations Review, vol. 17 (April 1964), pp. 454-69. The procyclical sensitivity of the labor force is also stressed by the researchers at the Urban Institute, using gross-flow data. See, for example, Ralph E. Smith, "A Simulation Model of the Demographic Composition of Employment, Unemployment, and Labor Force Participation," in Ronald G. Ehrenberg, ed., Research in Labor Economics (Greenwich: JAI Press, 1977), pp. 259-303. 
where $L F P R_{i}$ is the participation rate of the ith group, $U$ is an aggregate unemployment rate, $T_{i}$ is the time trend(s) for the $i$ th group, and $L F P R_{t-1, i}$ is a lagged dependent variable operating as a distributed-lag generator.

The hypothesis is that $f_{U}<0$ captures the discouraged-worker effect. This effect is open to different interpretations. In the traditional discouraged-worker model, the dropouts are a reserve army of Keynesian unemployment, even though they report themselves as being out of the labor force. These individuals are willing to work regularly at going wage rates and are not actively seeking work only because jobs are not available. On this interpretation the unemployment count is presumed to understate the available labor supply by the number of discouraged workers.

Alternatively, workers may leave the labor market because market wages are temporarily low relative to their reservation wage. A decrease in employment may lower the real or perceived market wage faster than the reservation wage, which is linked more closely to noncyclical factors such as the level of public assistance or the value attached to leisure. In this case, the workers who leave the labor force as a result of the drop in aggregate demand are not a hidden reserve of labor inputs at the current array of wages and prices. Rather, they are correctly measured as being out of the labor force and should not be included in the unemployment statistics.

The time-trend variable is also open to differing interpretations. For some researchers, trend variables capture the century-long shift from home work to market work on the part of women. In the Becker-Mincer model, the increased supply of market work is due to the increased relative productivity of market work over home work or the lower income elasticity of demand for home-produced goods compared with marketproduced goods. ${ }^{3}$ As wage rates have risen and have raised family income and the "cost" of time, families have shifted their consumption away from the relatively time-intensive goods that are produced in the home by family members toward market goods with a low relative time cost. This

3. Gary S. Becker, "A Theory of the Allocation of Time," Economic Journal, vol. 75 (September 1965), pp. 493-517, and Jacob Mincer, "Market Prices, Opportunity Costs, and Income Effects," in Carl F. Christ and others, Measurement in Economics: Studies in Mathematical Economics and Econometrics in Memory of Yehuda Grunfeld (Stanford University Press, 1963), pp. 67-82. 
has induced family workers, traditionally the females, to shift their work from the home to the market.

Other economists and most demographers prefer a less neoclassical, more sociological, explanation of participation trends, especially the marked acceleration since the late 1960s. Such an approach may emphasize the exogenous change in tastes associated with the "women's movement." This view has some appeal since no earlier model successfully predicted the sharp upswing in the trend rate of growth of female participation.

The most recent estimate of the discouraged-worker model is provided by Perry. He used two time trends, with the second beginning in 1967, to capture the longer-run influences and the sharp acceleration in participation of young women in the 1960s. The participation rates estimated by the U.S. Bureau of Labor Statistics were adjusted for several factors, using, in particular, Denison's method of converting household data on the labor force to establishment data. Using Perry weighted unemployment in place of measured unemployment resulted in equations of the form ${ }^{4}$

$$
L F P R_{i}=f\left(U_{P}, T, T 67\right),
$$

where $U_{P}$ is Perry weighted unemployment and $T$ is a continuous time trend while $T 67$ is a second time trend that begins in 1967. Here and in all subsequent equations the dependent variable was the natural logarithm of LFPR. For the periods 1949-75 and 1954-75, Perry found significant coefficients for most variables for each age-sex group.

The strength of the estimated discouraged-worker effect varies with the data set. I reestimated these equations, using the household series revised to account for the 1967 change in definitions, for both annual and quarterly data. ${ }^{5}$ The annual model is estimated for $1949-76$ in the form

$$
L F P R_{i}=f\left(U_{P}, T, T 67, \operatorname{LFPR}_{t-1, i}\right),
$$

4. Perry, "Potential Output."

5. My revision of the data for the 1967 change in definition relies on Robert L. Stein, "New Definitions for Employment and Unemployment," Employment and Earnings, vol. 13 (February 1967), pp. 3-27. Although the 1967 revision affects unemployment rates significantly, its effect on labor-force participation is less important. Stein has suggested that, since any specific revision was arbitrary and not based on significant differences in the data, he favored the unrevised series. The equations were estimated using both the revised and published BLS data, and the differences between the two sets of results were small. I used the revised data in the tables only because doing so facilitated comparisons with other labor-force studies. 
and is shown in table $1 .^{6}$ The discouraged-worker effect is generally less significant and has a smaller coefficient than Perry found. ${ }^{7}$

Whether the establishment data or the household data are appropriate depends upon the issue being investigated. My concentration is on the unemployment issue so that the household data are most useful. Given Perry's concern with potential output, a conversion to establishment-based data was desirable. Hereafter, the results are reported only for the household participation series (revised for the 1967 change in definitions).

Regardless of the specification, the time trends are plainly important independent variables and the broken time trend always improves the performance of the equation. Although trends help the equation fit better over the sample period, they do not convey information on the actual mechanism generating the change. Would an ongoing women's movement imply that the next cohort of young women will take on the rate of change or the level of the participation rate of the current cohort? Will the young women carry their labor-market attachment with them as they age, thereby causing the participation rates of older women to increase rapidly? The trend variables of equation 3 extrapolated into the future suggest continued rapid supply increases for young women, but little change in participation for older workers. That implies that the women's movement will have an increasing influence on young women, but that they will drop out of it when they age. This view has obvious drawbacks.

The above structure should incorporate variables that contain in-

6. For younger men, the size of the armed forces divided by total civilian noninstitutional population is included as an additional explanatory variable. This procedure is needed because the dependent variable is the civilian labor force, while increases in the armed forces are drawn largely from young males in the labor force rather than in school or at home.

7. Rather than using a lagged dependent variable, Perry adjusted his equations for autocorrelation using a first-order Cochrane-Orcutt scheme. As a result, the "long-run" discouraged-worker coefficients are open to different interpretations. I also estimated the various equations using the Cochrane-Orcutt adjustment in place of the lagged dependent variables, and the overall results were largely unchanged. Several variants on equation 3 were estimated. These included using regular unemployment, long-duration unemployment, and my UGAP series (a measure of labormarket tightness defined in Michael L. Wachter, "The Changing Cyclical Responsiveness of Wage Inflation," $B P E A, 1: 1976$, p. 126). Inflation variables were also only moderately successful in capturing a short-run cyclical response of participation rates. Using quarterly data for the period 1954-76 revealed a significant discouragedworker effect. In this case, the unemployment variable was introduced with a long polynomial lag. 
formation on the changes in cohorts in each age group over time. For example, the current group of workers aged 20 to 24 are from the unusually large baby-boom cohort. Ten years from now, that cohort will have moved up the age structure and the 20 -to- 24 population will be drawn from the beginnings of the "baby bust" generation.

\section{Cohort-Effect Variables}

The next two sections introduce into the participation equations variables that contain cohort information. The first summarizes the age structure of the working-age population. The specific variable used here is the percentage of persons aged 16 to 34 relative to the total civilian population aged 16 and over $\left(R P_{y}\right) .{ }^{8}$ It is introduced into the participation equation in place of $T 67$; that is,

$$
L F P R_{i}=f\left(U_{P}, T_{i},{ }^{\circ} R P_{y}, L F P R_{t-1, i}\right) .
$$

Such a variable is based on the assumption that the various age-sex groups are imperfect substitutes for one another. Young workers and new entrants into the labor market in general lack specific training and therefore cannot compete effectively with prime-age males, who have acquired this training as a consequence of their ongoing labor-market attachment. An imbalance of young workers resulting, for example, from the entry of the baby-boom cohorts into the labor force, has a twofold effect. First, as a consequence of relatively fixed factors of production in the short run and imperfect relative-wage adjustments, possibly due to the minimum wage and government transfer payments, the younger cohorts and most female groups suffer an increase in relative unemployment rates. ${ }^{9}$

Second, although relative wages are not flexible enough to clear the market, they are not perfectly rigid. The result is a decrease in hourly wage rates for secondary workers; and ceteris paribus, a decrease in family income. The mechanism through which changes in wages or income affect participation I call the relative-income effect.

8. In ibid., the numerator was individuals between the ages of 16 and 24 . That variable did not work well for the participation equations, but the variable used here is significant in both the participation-rate and labor-force equations. The two constructs are very similar but are out of phase with each other by about five years.

9. This effect provided the basis of the $U_{N}$ series reported in ibid. 


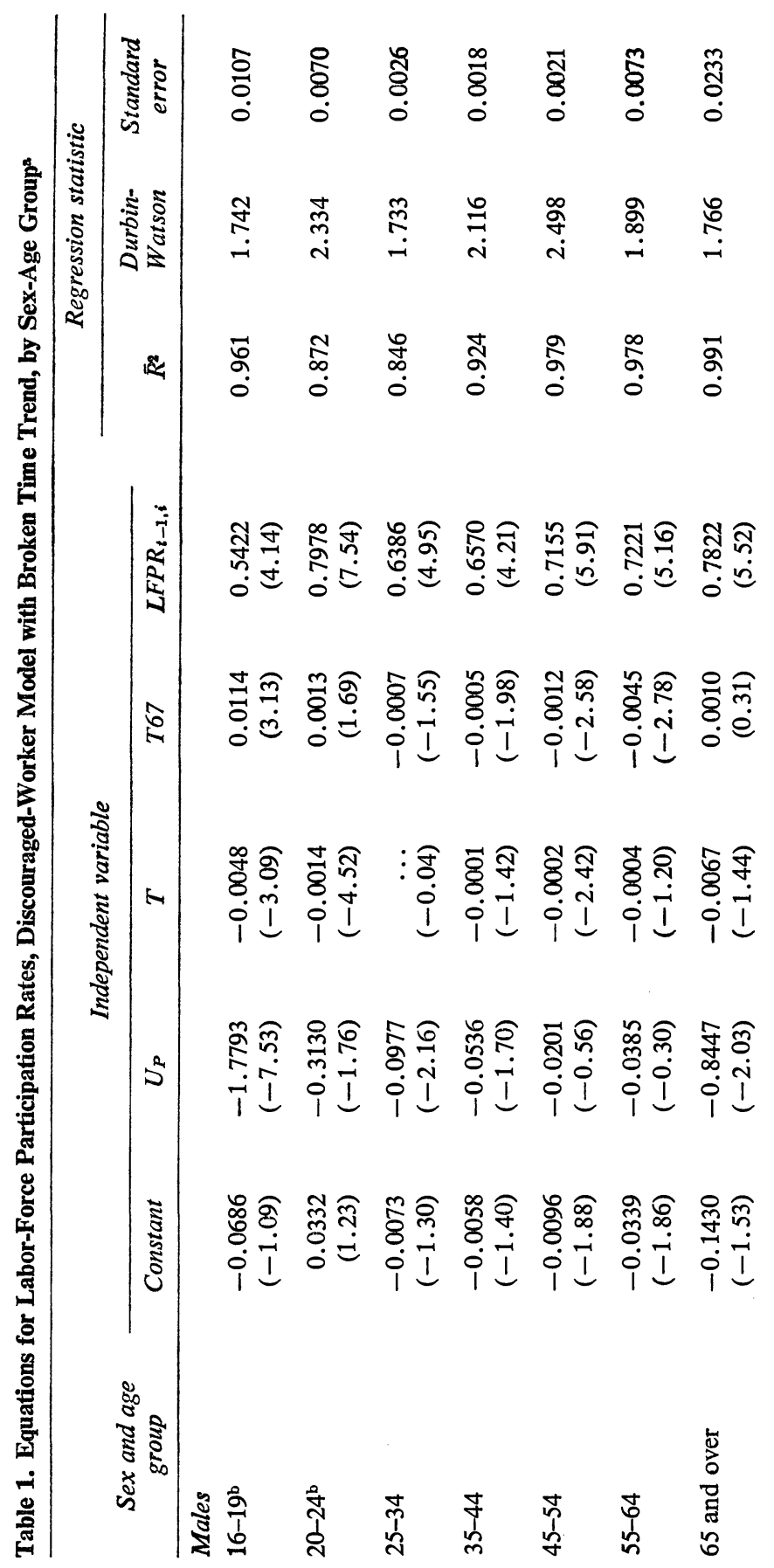




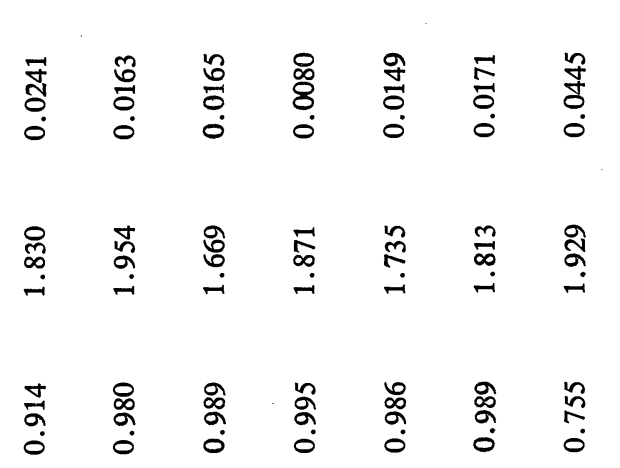

กินร

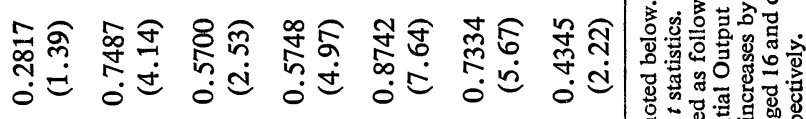

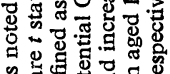

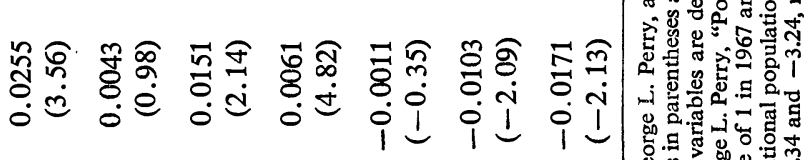

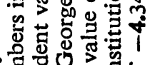

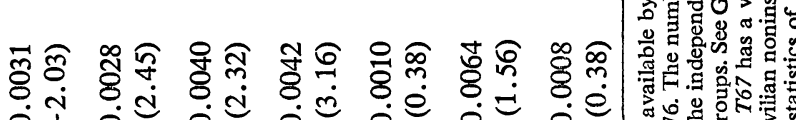

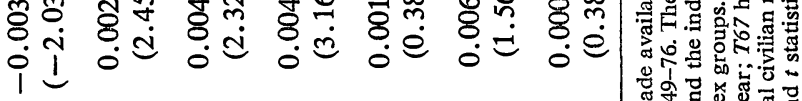

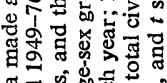

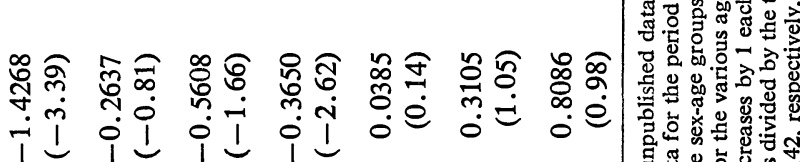

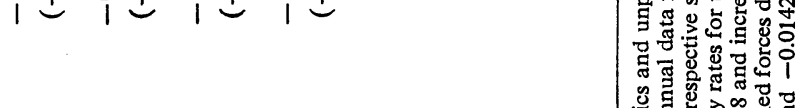
ڤి

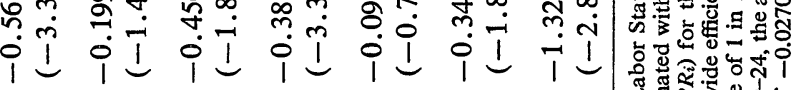

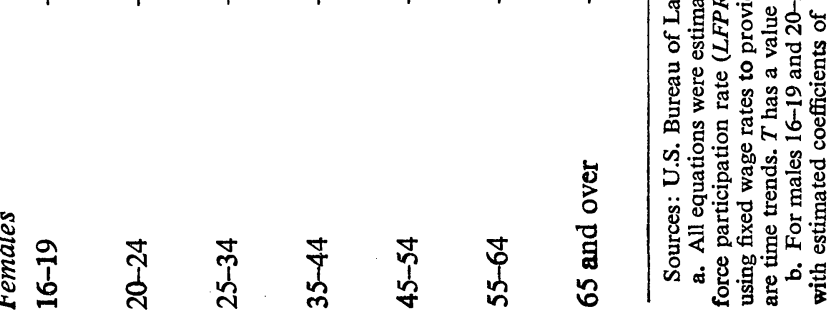


THE RELATIVE-INCOME MODEL

The relative-income model is relevant to secondary workers and is based on a type of negative income effect between market work and other activities, especially nonmarket work; ${ }^{10}$ that is, the underlying participation function is of the form

$$
L F P R_{i}=f_{i}\left(U_{P}, T_{i}, W_{i} / W^{*}\right), f_{W^{i} / W^{*}}<0,
$$

where $W$ is current family income and $W^{*}$ is the anticipated or desired level. The $W^{*}$ construct is likely to be a function of past own-family income and the current family income of other age groups:

$$
W_{i, t}^{*}=g\left(\sum \alpha_{i} W_{i, t-i}, \sum \beta_{j} W_{j, t}\right),
$$

where the $\alpha \mathrm{s}$ and $\beta \mathrm{s}$ are weights, and the is refer to a particular group and the $j$ s to other groups. The first term reflects the own lagged aspiration effect while the second term measures the contemporaneous influence of "keeping up with the other cohorts."

Although relative-income theory will be discussed in terms of equations 5 and 6, the empirical results are presented in terms of equation 4 and variations on that form, for reasons discussed below.

The relative-income model appears to contradict the cross-section evidence which shows participation of women increasing strongly with respect to their real wage and decreasing, but by a lesser magnitude, with respect to the wage of men. In fact, to the extent that the cross-section evidence is at all relevant to the time-series data, there is no contradiction. First, the income and substitution effects of the cross-section data are especially difficult to estimate in a time-series context in which real wages of both men and women trace generally upward trends with little independent variation between them. In terms of equation 5 the cross-section wage effects must be blended into a single term, and it makes little difference whether this term is a real-wage or trend term. The finding that the trend term has a positive sign for most female groups coincides with the

10. The relative-income model, as first applied to fluctuations in labor-force participation, was discussed in Michael L. Wachter, "A Labor Supply Model for Secondary Workers," Review of Economics and Statistics, vol. 54 (May 1972), pp. 141-51. The model draws from Easterlin's use of relative income to explain fertility swings, and from James S. Duesenberry, Income, Saving, and the Theory of Consumer Behavior (Harvard University Press, 1949). 
cross-section notion that the own-wage effects of young women are positive and are stronger than the negative effect of their spouse's wage. ${ }^{11}$

Second, the relative-wage effect, $W / W^{*}$, is not directly related to the cross-section evidence. There is an explicit assumption that tastes are regularly changing over time. Individuals and families do not react simply to the level of wages, but rather to the actual level relative to their aspirations. Although aspirations are measured by an economic variable, $W^{*}$, wage effects on participation rates involve both the influence of tastes and shifts in the budget constraint. The a priori notion of the relative-wage theory is that family income, which is closely but not solely associated with the primary worker's wage, is dominant. The basic hypothesis is that a decline in $W$, for a constant $\mathrm{W}^{*}$, causes secondary workers to switch from home or school work to market work in order to maintain the family's standard of living.

The overall impact of the secondary worker's wage is more complex. I have argued elsewhere that the impact should differ among age groups, being negative for younger women and positive for older ones. ${ }^{12}$ For younger women, the own-wage supply curve-for a given level of $W^{*}$ is backward or negatively sloped. Short-run downswings (upswings) in $W$, for given $W^{*}$, cause an increase (decrease) in participation rates. On the other hand, steady-state increases in $W$, where $W=W^{*}$, cause a movement up the long-run positively sloped supply curve.

For the current period, the $W / W^{*}$ effect predicts a ceteris paribus increase in the participation rate of young women and a decrease in the rate for older workers. Since the unbalanced age structure stemming from the baby boom depresses labor-market conditions for young and secondary workers in general, relative wages for both male and female young workers decline. Faced with a drop in $W / W^{*}$, families respond by reducing completed family size and shifting the secondary worker from home work to market work. ${ }^{13}$

11. It is recognized that the wage effects of either the cross-section or time-series data are largely concerned with the interoccupational decision between market and home work. Since it is usually difficult to separate leisure from home work in the available data, the wage effect captures an amalgam of the choice between work and leisure and that between market and home work.

12. The differences reflect life-cycle effects associated with changing needs for time and money associated with such factors as child rearing. See Wachter, "Labor Supply Model."

13. The reduction in the earnings prospects of young people also results in an increase in the proportion of the nonmarried which similarly increases the participation rate of women. 
Table 2. Median Income of Full-Time, Year-Round Male Workers, by Age, Relative to Males 45-54, Selected Years 1955-75

\begin{tabular}{lcccccc}
\hline Age group & 1955 & 1960 & 1965 & 1970 & 1973 & 1975 \\
\hline $14-19$ & $0.4159 \mathrm{a}$ & 0.3476 & $0.3592^{\mathrm{b}}$ & 0.3977 & 0.3752 & 0.3820 \\
$20-24$ & 0.7331 & 0.6897 & 0.6882 & 0.6701 & 0.5858 & 0.5754 \\
$25-34$ & 0.9593 & 0.9598 & 0.9557 & 0.9189 & 0.8878 & 0.8628 \\
$35-44$ & 1.0049 & 1.0403 & 1.0524 & 1.0329 & 1.0120 & 0.9947 \\
$45-54$ & 1.0000 & 1.0000 & 1.0000 & 1.0000 & 1.0000 & 1.0000 \\
$55-64$ & 0.8816 & 0.8945 & 0.9196 & 0.9134 & 0.9194 & 0.9129 \\
65 and over & 0.6698 & 0.7247 & 0.7458 & 0.6801 & 0.6995 & 0.7782 \\
\hline
\end{tabular}

Source: U.S. Bureau of the Census, Current Population Reports, Series P-60, "Money Income in [year] of Families and Persons in the United States" (Government Printing Office), various issues, and unpublished data.

a. The 1950 data are used for males 14-19 because no value is reported for 1955 .

b. The 1964 data are used for males 14-19 because of obvious measurement problems with the 1965 data

For older women, the income picture has been more favorable than it has been for younger ones. Their own wage and unemployment experience may be somewhat unfavorable, because a certain percentage have slight labor-market attachment and hence are substitutes for young workers. However, their family income is maintained by the favorable market conditions for prime-age men. An improved labor market for their spouses coupled with the slack market for their own labor is likely to depress, ceteris paribus, the participation rate of older women.

\section{THE RELATIVE-WAGE DATA}

That young workers and their families have suffered a strong decline in relative family income is exhibited in tables 2 and 3. Table 2 shows the earnings of men who worked full time, year-round relative to those of men aged 45-54, while table 3 indicates relative family income for the various age groups measured against families whose head is $45-54$. The members of the baby boom begin to enter the labor force in the late 1950s and early 1960s and the drop in relative earnings of young workers and families is dramatic. These two sets of data illustrate different parts of the story of the decline of relative income of younger people. Since the data in table 2 exclude those who suffered any significant bouts of unemployment and those who work either part time or full time only part of the year it focuses specifically on deterioration in relative hourly or full-time earnings. For men 14-19, the decline in relative earnings is very slight; most of the labor-market deterioration for this group has shown up in in- 


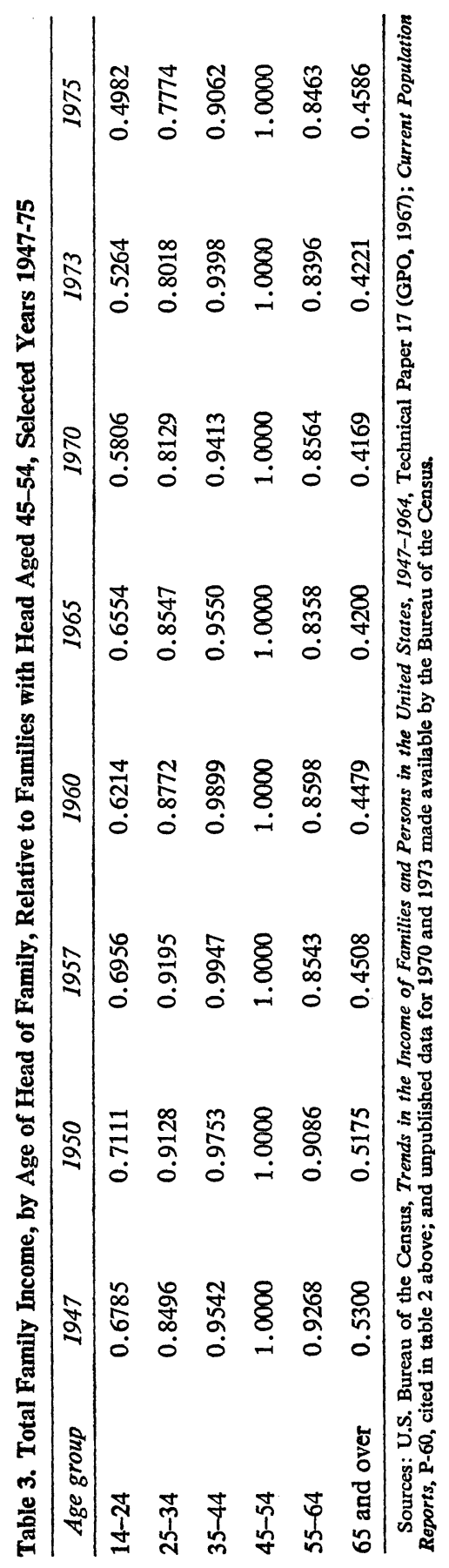


creased unemployment. For men 20-24, the decline in relative income between 1955 and 1975 is from 0.73 to 0.58 . In other words, while the average 20-24-year-old earned almost three-fourths of what a 45-54year-old worker earned in 1955, he earned only slightly more than half as much as in 1975. Men 25-34 have also experienced a significant decline between 1955 and 1975 whereas the earnings of all other groups of men have held steady or increased relative to those of the benchmark group. ${ }^{14}$

For young families in general, as distinct from individuals, income has also declined as a percentage of income of families whose head is 45 to 54 (table 3). For example, between 1957 and 1975, relative family income of those 14 to 24 years of age declined from 0.70 to 0.50 . For families whose head was 25 to 34 , the decline was from 0.92 to 0.78 . Since these data are for families, they are responsive to the effect of relative unemployment shifts and the increase in households with female heads. On the other hand, they also indicate that the increase in two-earner families, which has been concentrated in younger families, has not been sufficient to offset the deterioration in labor-market conditions for young workers. Young families with two wage earners have managed to soften the decline in relative income, but they have not managed to reverse it.

These data support the relative-income model and the key exogenous role of a variable like $R P_{y}$. First, the timing of the decline in relative income for young workers coincides with the entrance of the baby bulge into the labor market, starting in the late 1950s. For example, for most young families, income relative to that of families headed by a man aged 45 to 54 rose between 1947 and 1957 (table 3 ). The decline in the relative earnings (and the increase in unemployment rates) of young people has not been a long-term development, but appears to correspond to the intermediate-term swing in the age structure of the population. Second, the increase in participation rates for female groups is most marked for young people who experienced declines in their own relative income and

14. The data for year-round, full-time female workers indicate a decline for all age groups under 65 relative to men 45-54. Here again, however, the declines are most marked for younger women. This indicates that the baby-boom generation of younger workers has caused a general imbalance in the labor market for all secondary workers. Some of these points are also discussed by Robert J. Gordon, "Structural Unemployment and the Productivity of Women," in Karl Brunner and Allan H. Meltzer, eds., Stabilization of the Domestic and International Economy, CarnegieRochester Conference Series on Public Policy, vol. 5 (Amsterdam: North Holland, 1977), pp. 181-229. 
their family's relative income. Older women, with steady or rising relative family income, have increased their participation rates only slightly.

The $R P_{y}$ variable is used for estimation purposes rather than any of the direct relative-income measures for several reasons: First, whereas relative income is endogenous, $R P_{y}$ is exogenous to the participation equation; that is, the fall in relative income induces greater participation, but these increases in the labor supply, in turn, affect relative income. Second, the construction of an appropriate relative-income variable, involving both contemporaneous comparisons across age groups and lagged comparisons on past own behavior, poses a conceptual problem. It is complicated by the fact that the data series are not long enough to permit the inclusion of past income for each age-sex group. Finally, not only is $R P_{y}$ exogenous but its values through 1985 are known with some certainty. Since an important purpose of this paper is to analyze alternative forecasts of future participation rates, knowledge of the likely future course of $R P_{y}$ is useful.

\section{The Intermediate-Swings Model}

Table 4 shows the results obtained by replacing the broken trend $T 67$ with $R P_{y}$. The equations are in annual form for the period 1949-76. The age-structure variable is significant in ten of the fourteen equations. The $\bar{R}^{2}$ s of the equations are largely unchanged, while the significance level of $U_{P}$ rises for most male groups and falls for most female groups.

The $R P_{y}$ variable has a positive coefficient for men 16-24 and 65 and over, and for women 16-44. In other words, this variable resembles $T 67$ in that it has an identical sign in the various age-sex equations. I believe that $T 67$ in table 1 is acting as a proxy for those intermediate-swing factors associated with the entrance of the baby-boom cohorts into the labor market during the early $1960 \mathrm{~s}$. The $R P_{y}$ variable, on the other hand, is open to broader interpretations than the relative-income mechanism. Most significantly, the equations of table 4 present a much different picture of the coming decade from those of table 1 , as I shall show below.

\section{SCHOOL ENROLLMENT AND FERTILITY}

A number of modifications can be made to the equations of table 4 . First, school enrollment can be added to the equations for both young 


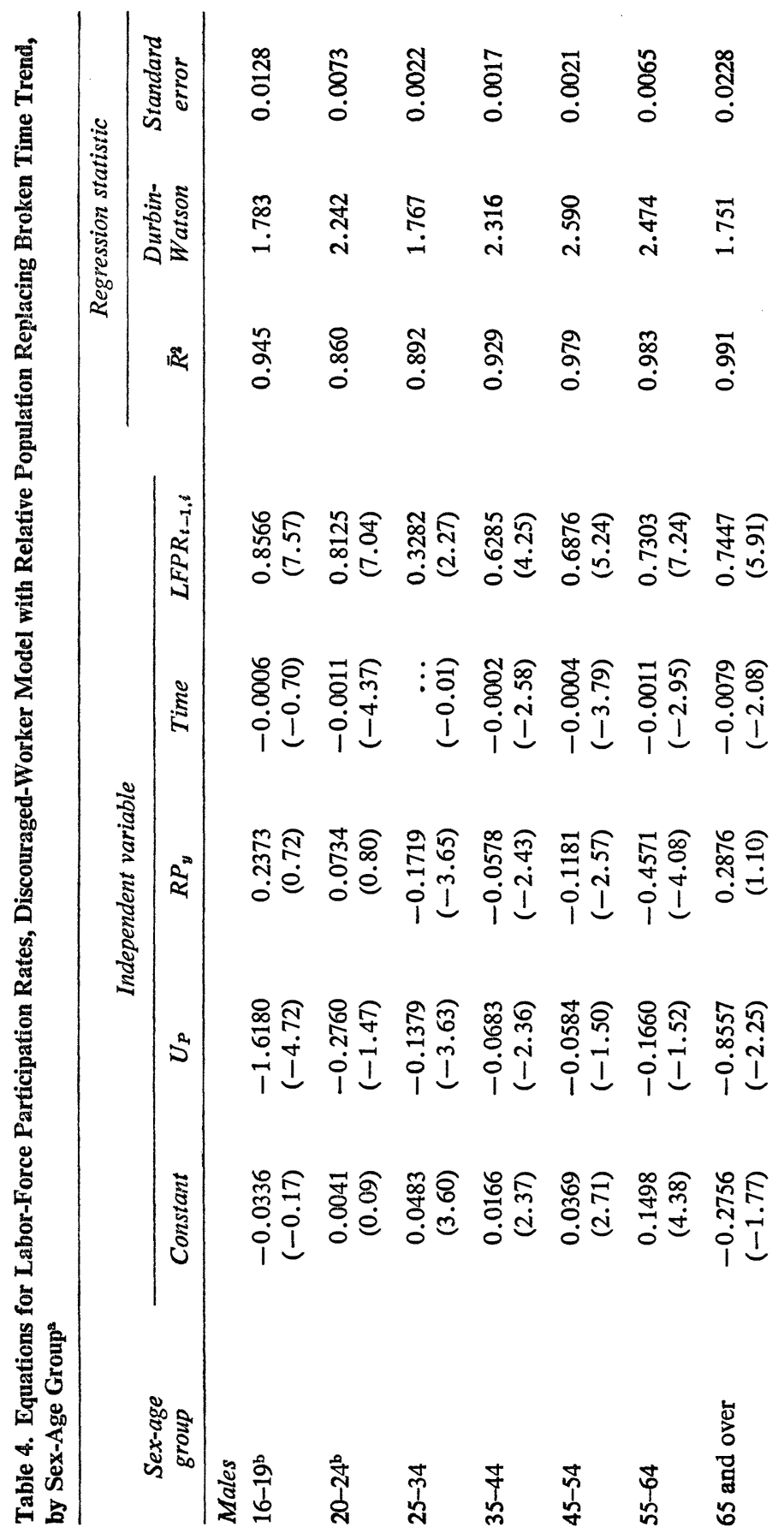




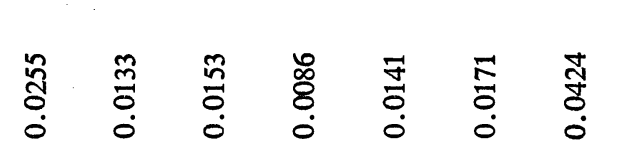

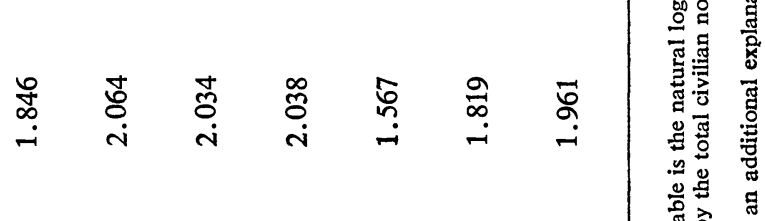

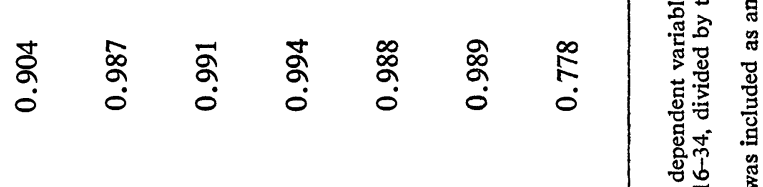

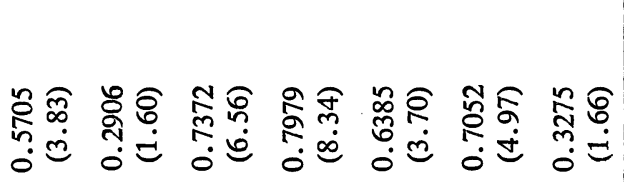
F

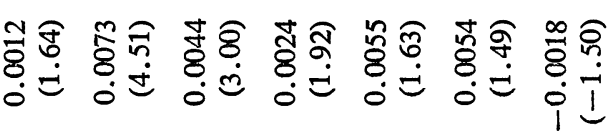

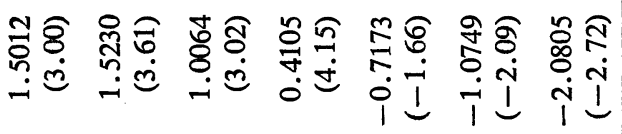

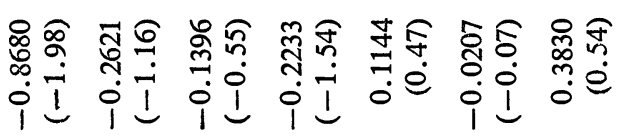

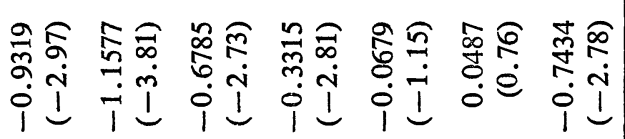

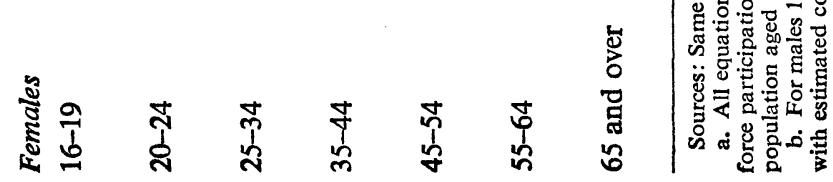


men and young women. In a purely accounting sense these variables should have negative signs since most individuals tend to be either in school or in the labor force. Using this variable introduces obvious simultaneity problems since school enrollment and participation decisions are likely to be made together. Its value is that, according to past experience, it keeps projections of participation rates compatible with projections of school enrollment. The school-enrollment variable has a quantitatively significant role in the participation equations. After growing significantly prior to 1970, enrollment rates have declined for males 16-24 and females 16-19 while increasing at a reduced rate for females 20-24. ${ }^{15}$

Second, the fertility rate can be added to help, along with $R P_{y}$, in capturing the influence of intermediate swings in women's participation rates. This variable is introduced lagged one year, to capture the overall socioeconomic climate of the relative-income effect that may underlie the revolution in the participation rates of women. As Perry has discussed, participation rates have increased for women who are having children as much as for those who are not having children; that is, the fertility rate cannot represent simply the shift to childless families, but rather, represents the amalgam of effects involved in the movement to smaller families. In general, the large cohort of young workers, the drop in their income, and the decline in fertility rates are all part of the intermediate-swings phenomenon that is correlated with the change in participation rates. ${ }^{16}$

Different fertility variables are entered into the equations for women, depending upon the age group. For the groups 16-19, 20-24, and 25-34,

15. I would argue that the intermediate-swings relative-income effect is also behind the recent trends in school enrollment. For example, the very size of the baby-boom cohort increases the difficulties that families have in financing education. In addition, to the extent that education represents a luxury consumption good (as well as an investment good), the reduction in permanent income depicted in tables 2 and 3 would also result in a cutback in education.

16. Attempts were made to include a social security variable in the equations for older workers and the minimum wage in the equations for younger ones, but the results were insignificant. A priori, it is unclear what direct effect minimum wages should have on participation rates. Empirically, Jacob Mincer, "Unemployment Effects of Minimum Wages," Journal of Political Economy, vol. 84 (August 1976, pt. 2), pp. S87-S104, calculates a significant negative effect; James F. Ragan, Jr., "Minimum Wages and the Youth Labor Market," Review of Economics and Statistics, vol. 59 (May 1977), pp. 129-36, finds no effect in either direction. Minimum wages have an important, but indirect effect on participation rates if they increase the overall unemployment rate and shift more of the burden of unemployment to teenagers. 
the age-specific total fertility rate (TFR) is used, lagged one year. For the older groups, the aggregate total fertility rate is used, but it is introduced with a lag that depends upon age. The aim is to capture the total fertility rate existing at the time the females were approximately 30 to 35 years of age and would have largely completed child bearing; that is, the fertility rate represents a cohort-effect variable that reflects conditions existing when each age group was in its child-bearing years.

For younger female groups, the anticipated sign on the fertility rate is clearly negative. For older groups, a priori restrictions are less obvious. In large families, once the children are older, the costs of their rearing may encourage secondary workers to enter the labor market. In this case, the sign on lagged fertility for females 35 and over may be positive. Alternatively, and more in the spirit of this model, the size of families reflects labor-market conditions for the cohort of the family head. If, for example, the current cohort of females 45-54 had large completed families, that would reflect positive economic factors at the time when they were having children. As a consequence of specific training, market work is habit forming, and women who do not work when they are young are also less likely to work when they are older.

The results, including all of the variables whose coefficients had a $t$ ratio exceeding unity, are shown in table 5. The school-enrollment variable clearly improves the specification of the equations for men aged 1619 and 20-24. The school-enrollment variable also improves the fit of the equation for women aged 16-19.

The total fertility rate has good results, but suffers somewhat from the high degree of collinearity with the $R P_{y}$ term. For women who are currently in the midst of their child-bearing years, 20-24 and 25-34, the fertility rate works better than $R P_{y}$ and reduces that variable to insignificance. For females $35-44$, for whom the total fertility rate is lagged ten years to capture the cohort effect, both $T F R$ and $R P_{y}$ are significant. For those aged 45-54 and 55-64, the $R P_{y}$ variable performs slightly better than $T F R$ lagged twenty and thirty years, respectively. Both can be included in the equation if one is lenient in the requisite confidence interval. (In a quarterly version of table 5, TFR improved the fit of the equation in place of $R P_{y}$ in five of the seven equations for females, including females 45-54 and 55-64.) For forecasting purposes, I have omitted $T F R$ from the equations for females $45-54$, but included both variables in the equation for those 55-64. 


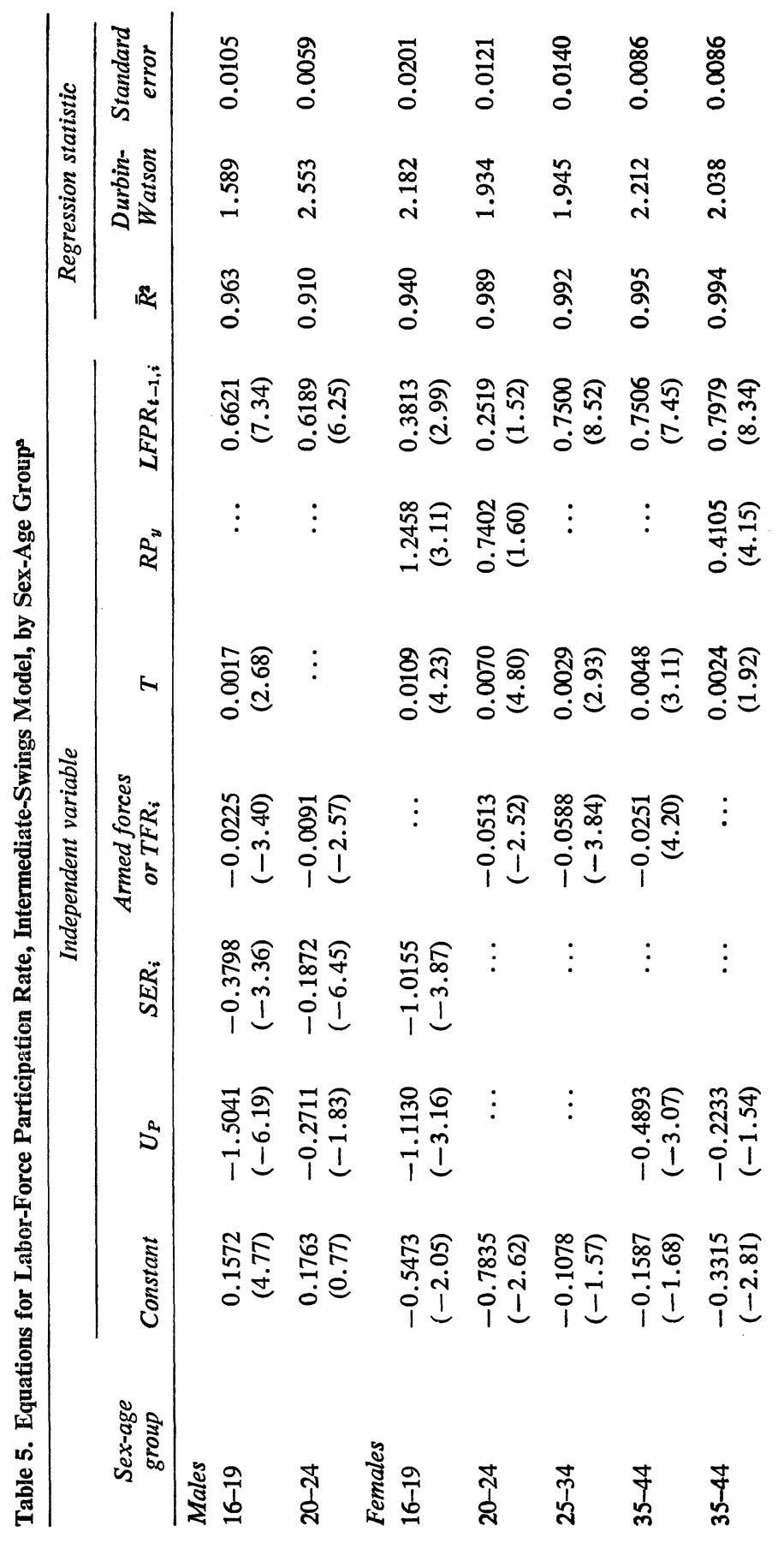




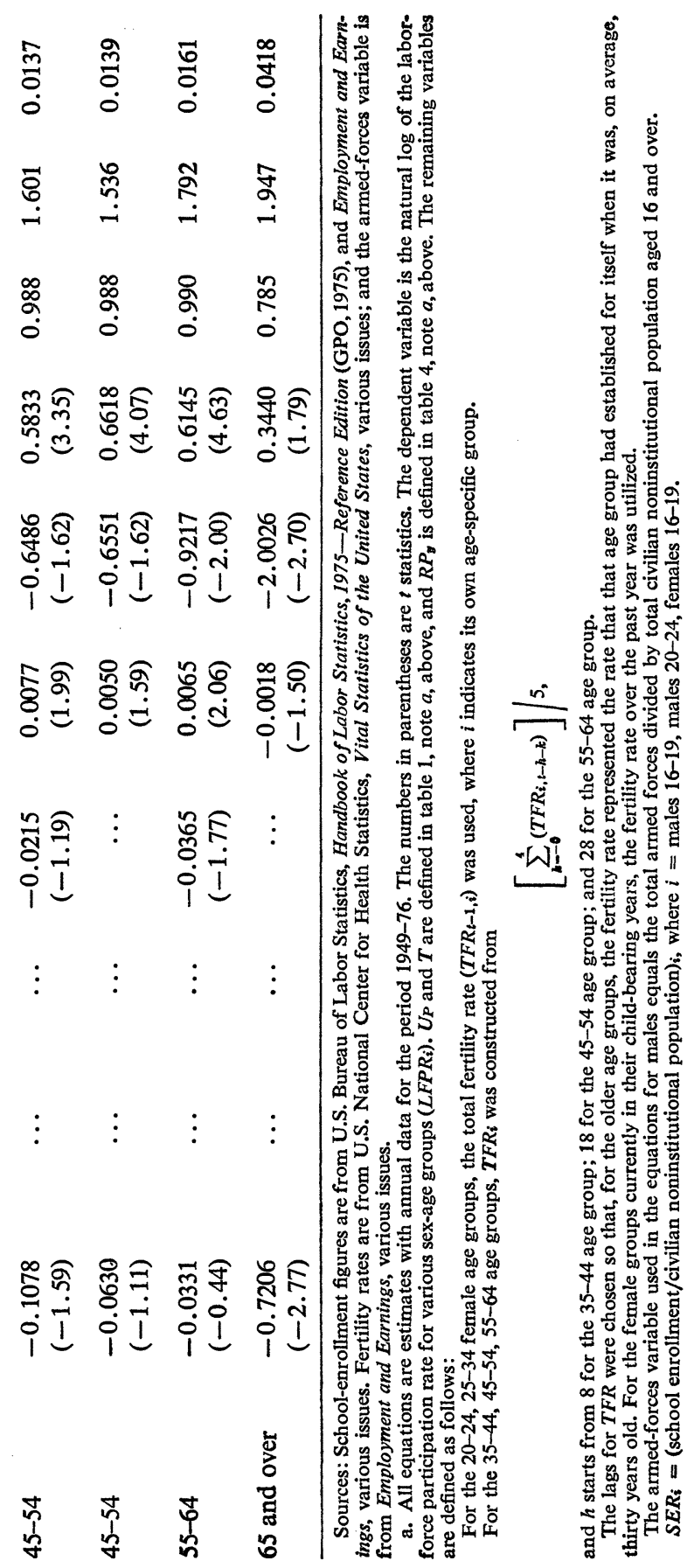


The workings of the cohort effect through $T F R$ are neatly illustrated by the 45-54 age group of women. Women in this age group during the 1950 s had been in their child-bearing years during the Great Depression. The $T F R_{-20}$ is therefore falling and participation rates are rising. By the late 1960s and early 1970s, the 45-54 age group is being populated by the women who had borne the baby boom. The sharp increase in $T F R_{-20}$ explains the ceteris paribus stability of participation rates among older groups during the recent past. By the mid-1980s, the baby-bust mothers with their low $T F R_{-20}$ will be $45-54$ and the participation rates for this age group should once again increase.

Although there can be some quarrel with the particular specifications of the equation in table 5 or the interpretation given to specific variables, I believe that they indicate the overwhelming quantitative importance of the intermediate-swings variables in the participation equations. The revolution in participation rates in the postwar period appears to be described best by the demographic twist in the population and the associated changes in fertility rates and relative income.

The alternative to the intermediate-swings approach for explaining noncyclical movements in participation is the exogenous sociological explanation for which time-trend variables serve as proxy. The correct approach cannot be ascertained simply by comparing the $\bar{R}^{2}$ s. The model presented in table 5 does have the advantage of having testable hypotheses that can lend themselves to forecasting. On the other hand, the sociological view associated with the women's movement is more amorphous and it does not pose obvious refutable hypotheses. Because the mechanisms underlying the trend variables are unknown, extrapolating trend-dominated equations into the future is hazardous.

An important caveat relevant to the participation equations presented here is that they predict 1976 quite poorly and are likely to underpredict 1977 by even more if the current rate of growth in the labor force continues. I conjecture that these inadequacies are due to the omission of government-policy variables concerning transfer payments. Eligibility for a number of public-assistance programs has been altered so as to require registration for work. In addition, the benefit period for unemployment compensation has been lengthened during recent downturns. These changes may have increased the number of individuals who report themselves as being unemployed rather than out of the labor force. Of course, the regulations governing public-assistance programs and unemployment 
compensation have been altered many times during the past generation in ways that may have affected participation, and careful analysis of this record would be required to isolate the quantitative importance of any recent changes.

\section{Discouraged-Worker Phenomenon}

Since equations for labor-force participation tend to focus on the magnitude of the discouraged-worker effect, it is useful to present the aggregate effect from the equations presented in this paper. The results are shown in table 6. For table 1, the equations using the broken time trend indicate a short-run change of the participation rate of 0.26 percentage point for a change of 1 percentage point in the unemployment rate. Using $R P_{y}$ in place of $T 67$ reduces this estimate to 0.21 . In table 5 the shortrun elasticities are even smaller. The long-run estimates of the number of discouraged workers assume that the $U_{P}$ effects grow for three years as the short-run effects feed through the lagged dependent variable. Feedbacks lagged beyond the first three years were ignored as it seemed unrealistic to assume that the process went further. Additional tests of the general participation equation suggest some caution in interpreting the long-run effects calculated in this way. First, omitting $L F P R_{\mathrm{t}-1}$ and adding lagged $U_{P}$ terms frequently resulted in insignificant lagged coefficients. Second, when the equations of tables 1,4 , and 5 were reestimated using the Cochrane-Orcutt scheme, most coefficients changed little, and, in this case, the overall short-run (and in this case total) discouraged-worker effect was under 0.26 .

The age-sex composition of discouraged workers is interesting. First, in the short-run effect about 50 percent are 16-19, and about two-thirds are 16-24. It appears that there are few discouraged workers over the age of 24 . Since teenagers tend to be located in the relatively acyclical service sector and have the least cyclically sensitive age-specific unemployment rates, this result is puzzling. ${ }^{17}$ In part this may reflect the influence that minimum wages and government transfer policies have on the

17. In Wachter, "Changing Responsiveness," the coefficient on the unemployment rate for prime-age men was 0.60 when men $16-19$ were the dependent variable and 0.38 when women 16-19 were the dependent variable. For both sexes, the teenage groups had the smallest coefficient on cyclical unemployment for any agesex group. 
Table 6. Size of the Labor Force and Estimated Number of Discouraged Workers, by Age-Sex Group, Alternative Models, 1976a

Thousands

\begin{tabular}{|c|c|c|c|c|c|}
\hline \multirow{3}{*}{$\begin{array}{l}\text { Sex and age } \\
\text { group }\end{array}$} & \multirow[b]{3}{*}{ Labor force } & \multicolumn{4}{|c|}{ Discouraged workers } \\
\hline & & \multicolumn{2}{|c|}{$\begin{array}{c}\text { Model with } \\
\text { broken time trend }\end{array}$} & \multicolumn{2}{|c|}{$\begin{array}{l}\text { Model with } \\
\text { relative population }\end{array}$} \\
\hline & & Short run & Long run & Short run & Long run ${ }^{\mathrm{b}}$ \\
\hline \multicolumn{6}{|l|}{ Males } \\
\hline $16-19$ & 4,832 & 151.15 & 301.64 & 137.26 & 441.80 \\
\hline $20-24$ & 7,666 & 41.69 & 122.66 & 36.76 & 110.61 \\
\hline $25-34$ & 14,383 & 24.36 & 56.20 & 34.40 & 50.61 \\
\hline $35-44$ & 10,370 & 9.64 & 22.87 & 12.28 & 27.90 \\
\hline $45-54$ & 10,322 & 3.59 & 9.31 & 10.45 & 25.97 \\
\hline $55-64$ & 6,972 & 4.65 & 12.13 & 20.07 & 53.24 \\
\hline 65 and over & 1,816 & 26.70 & 76.70 & 27.05 & 73.37 \\
\hline Total & 56,359 & 261.78 & 601.51 & 278.27 & 783.36 \\
\hline \multicolumn{6}{|l|}{ Females. } \\
\hline $16-19$ & 4,138 & 103.56 & 143.26 & 62.70 & 130.52 \\
\hline $20-24$ & 6,280 & 28.74 & 78.42 & 28.56 & 39.97 \\
\hline $25-34$ & 9,160 & 89.42 & 185.99 & 22.18 & 59.47 \\
\hline $35-44$ & 6,801 & 43.15 & 90.40 & 26.37 & 77.59 \\
\hline $45-54$ & 6,669 & -4.45 & -14.71 & -13.20 & -30.44 \\
\hline $55-64$ & 4,308 & -23.09 & -61.55 & 1.54 & 3.93 \\
\hline 65 and over & 1,058 & -14.82 & -25.27 & -7.05 & -10.36 \\
\hline Total & 38,414 & 222.51 & 396.54 & 121.10 & 270.68 \\
\hline $\begin{array}{l}\text { Total, male } \\
\text { and female }\end{array}$ & 94,773 & 484.29 & 998.05 & 399.37 & $1,054.04$ \\
\hline \multicolumn{6}{|c|}{$\begin{array}{l}\text { Increase in participation } \\
\text { rate, } L F P R \text {, from } 1 \\
\text { point change in } U\end{array}$} \\
\hline
\end{tabular}

Sources: Based on the regression results of tables 1 and 4, above. Figures are rounded.

a. The numbers in the table are based on the assumption that weighted unemployment, $U_{P}$, changes from 5.80 percent to 4.07 percent $\left(\Delta U_{P}=-1.73\right)$. This change is (approximately) comparable to a 2 percent change in the unemployment rate reported by the Bureau of Labor Statistics.

b. The number for long-run discouraged workers is calculated as the sum of discouraged workers from period $t$ through $t-3$. See text.

labor market for teenagers. In particular, since many auction markets are cut off from teenage employment because of minimum wages and because teenagers are frequently not eligible for transfer insurance, these young workers drop out of the labor force rather than remain in the ranks of the unemployed. In addition, the voluntary movement between school and market work makes it difficult to interpret, for policy purposes, the number of teenage discouraged workers. 
Second, the heavy weighting of teenagers implies a lower effective number of discouraged workers. This follows from either Perry's efficiency rating of workers or my normalized unemployment rates $\left(U_{N I_{i}}\right)$ for the various age-sex groups. ${ }^{18}$

Third, the tendency of the discouraged-worker variable to be more significant in the equations for prime-age men than in those for secondary workers sharply reverses the results of previous discouraged-worker models. As noted earlier in connection with the poor predictions of these equations for recent years, one may conjecture that changing government regulations have reduced the cyclical sensitivity of secondary workers and that these recent years dominate the regression estimates. For prime-age males the presence of a significant discouraged-worker effect may reflect an asymmetric cyclical response for this group. For males 25 and over, participation rates have declined secularly, with the largest declines heavily concentrated in the older groups. The data suggest that periods of high unemployment speed the secular decline, but that participation rates for these groups do not recover as the labor market improves. In other words, high $U_{P}$ hastens exit from the labor market, but low $U_{P}$ does not uncover a reserve of unemployed. If this interpretation is correct, $U_{P}$ calculations overstate the true pool of discouraged workers, especially for older male workers.

\section{Forecasting Participation Rates}

Over the past decade, growth in the labor force has been systematically greater than expected by the standard equations incorporating a single historical trend plus discouraged-worker effects. In forecasting participation rates today there are two central questions. First, will the overall rate continue growing at its very rapid recent pace? Second, will the growth in aggregate participation rates continue to be due solely, or even largely, to the growth in the participation of younger females?

To answer these questions I contrast the forecasts for 1981 and 1986 implicit in the equations of table 5 with the trend-dominated equations of table 1 and with simpler trend-extrapolation methods. The results are shown in table 7. To generate the forecasts in that table, I assume that (1) the trend values follow their predetermined path, with the trend

18. Ibid. 
Table 7. Labor-Force Participation Rates, 1976 Actual, and 1981 and 1986 Projected

\begin{tabular}{|c|c|c|c|c|c|c|c|}
\hline \multirow[b]{2}{*}{$\begin{array}{l}\text { Sex and } \\
\text { age group }\end{array}$} & \multirow[b]{2}{*}{$\frac{1976}{\begin{array}{c}\text { Actual } \\
(1)\end{array}}$} & \multicolumn{3}{|c|}{1981} & \multicolumn{3}{|c|}{1986} \\
\hline & & $\begin{array}{l}\text { Dis- } \\
\text { couraged- } \\
\text { worker } \\
\text { model } \\
(2)\end{array}$ & $\begin{array}{l}\text { Extrapo- } \\
\text { lation } \\
\text { (3) }\end{array}$ & $\begin{array}{l}\text { Inter- } \\
\text { mediate- } \\
\text { swings } \\
\text { model } \\
(4)\end{array}$ & $\begin{array}{c}\text { Dis- } \\
\text { couraged- } \\
\text { worker } \\
\text { model } \\
(5)\end{array}$ & $\begin{array}{l}\text { Extrapo- } \\
\text { lation } \\
(6)\end{array}$ & $\begin{array}{c}\text { Inter- } \\
\text { mediate- } \\
\text { swings } \\
\text { model } \\
(7)\end{array}$ \\
\hline \multicolumn{8}{|l|}{ Males } \\
\hline $16-19$ & 0.594 & 0.665 & 0.615 & 0.611 & 0.723 & 0.637 & 0.629 \\
\hline $20-24$ & 0.852 & 0.866 & 0.857 & 0.852 & 0.874 & 0.861 & 0.851 \\
\hline $25-34$ & 0.953 & 0.944 & 0.943 & 0.953 & 0.936 & 0.932 & 0.959 \\
\hline $35-44$ & 0.955 & 0.947 & 0.944 & 0.952 & 0.939 & 0.934 & 0.953 \\
\hline $45-54$ & 0.916 & 0.895 & 0.897 & 0.908 & 0.874 & 0.877 & 0.907 \\
\hline $55-64$ & 0.745 & 0.683 & 0.690 & 0.720 & 0.626 & 0.635 & 0.719 \\
\hline $\begin{array}{r}65 \text { and } \\
\text { over }\end{array}$ & 0.203 & 0.179 & 0.165 & 0.179 & 0.159 & 0.126 & 0.155 \\
\hline \multicolumn{8}{|l|}{ Females } \\
\hline $16-19$ & 0.499 & 0.605 & 0.546 & 0.550 & 0.708 & 0.592 & 0.578 \\
\hline $20-24$ & 0.650 & 0.750 & 0.715 & 0.675 & 0.868 & 0.780 & 0.690 \\
\hline $25-34$ & 0.571 & 0.714 & 0.656 & 0.609 & 0.895 & 0.740 & 0.627 \\
\hline $35-44$ & 0.578 & 0.651 & 0.632 & 0.627 & 0.736 & 0.686 & 0.660 \\
\hline $45-54$ & 0.550 & 0.555 & 0.567 & 0.581 & 0.557 & 0.585 & 0.642 \\
\hline $55-64$ & 0.411 & 0.381 & 0.403 & 0.420 & 0.352 & 0.396 & 0.456 \\
\hline $\begin{array}{r}65 \text { and } \\
\text { over }\end{array}$ & 0.083 & 0.070 & 0.075 & 0.081 & 0.061 & 0.068 & 0.085 \\
\hline
\end{tabular}

Sources: Column 1 is from the U.S. Bureau of Labor Statistics. Columns 2 and 5 are derived from the equations in table 1 above. Columns 4 and 7 are derived from the equations in table 5 above. Columns 3 and 6 are estimated by projecting the growth rate in the past ten years (1967-76) for each sex-age group into the next ten years (1977-86). The rate of growth is assumed to be the same for each year.

extrapolations growing over the next ten years at the rate set in the past ten years; ${ }^{19}(2)$ the $R P_{y}$ variable grows slowly between 1977 and 1980 and then declines as predicted by the Census Bureau's population estimates; (3) the fertility variables reverse direction and grow slowly, attaining the levels implied by zero population growth in 1981 and remaining constant thereafter; (4) the school-enrollment rates recover from their recession lows and recoup part of their loss by attaining their 1972 values; (5) the armed forces remain a constant percentage of the population; and (6) $U_{P}$ declines to its 1972 value.

19. The difference in forecasts between using a broken time trend and a single time trend is not significant for most groups. Since the broken time trend fits much better over the estimation period, I employ equation 3 as a counterpoint to my equations in table 5. The trend-extrapolation method is not really the one used by Perry in "Potential Output"; he extended, for five years, the average annual absolute increases of the previous decade. 
The broken time trend projects a large increase in participation rates for men 16-19 and women 16-54. For most groups of men and for older women, participation rates are projected to fall slightly. These changes are magnified if the equations are run out to 1986 since, by that point, the discouraged workers are all in the labor force and the remaining effect is a pure trend. The projections for equation 3 are shown in columns 2 and 5 of table $7 .^{20}$

The projections for 1981 based on my equations are shown in column 4 of table 7. Given the stress on cohort effects and the aging of the babyboom cohort, my equations systematically predict relatively slower rates of labor-force growth for younger women and faster rates for older women. I also predict slower rates of growth for men 16-24. For older men, all models continue to project very moderate declines.

The differences in the forecasts of the broken-trend and intermediateswings equations are highlighted by examining the groups of women aged 25-34 and 45-54. The table 5 equations forecast a gain of 3.8 percentage points for the first group and a similar 3.1 point gain for the second. The table 1 equations indicate a 14.3 point increase for women $25-34$ and a 0.5 increase for women $45-54$. These differences are further accentuated in the 1986 forecast.

The results of the extrapolation of the past ten years (1967-76) into the next ten years (1977-86) are shown in columns 3 and 6 of table 7. Lacking the extra push of the broken trend, these forecasts fall between the results obtained from tables 1 and 5. They continue to feature rising rates for younger men and women, relatively stable rates for older women, and falling rates for older men.

The key to explaining the differing time paths for younger and older workers lies in the intermediate-swings variables $R P_{y}$ and $T F R$. These generally reduce the coefficient on the time trend; moreover, while the trend variables continue their sample-period path into the forecast period, both $R P_{y}$ and $T F R$ break with their pre-1976 path. This captures the aging of the baby-boom cohort. By 1986 the vanguard of the oversized

20. Trend models, of course, are not meant to be extrapolated over periods as long as ten years, and some users, such as the Bureau of Labor Statistics, modify their trend model even for near-term projections. The BLS method is to calculate the average rate of growth over the past years and then to assume that that growth rate slowly approaches zero over the next twenty years. In other words, the trend is forced to zero. See Howard N. Fullerton, Jr., and Paul O. Flaim, "New Labor Force Projections to 1990," Monthly Labor Review, vol. 99 (December 1976), pp. 3-13. 
Table 8. Projected Change in Total Labor Force, by Model, 1978-86

Percent

\begin{tabular}{ccc}
\hline Year & $\begin{array}{c}\text { Intermediate- } \\
\text { swings } \\
\text { model }\end{array}$ & $\begin{array}{c}\text { Discouraged- } \\
\text { worker model } \\
\text { with broken } \\
\text { time trend }\end{array}$ \\
\hline 1978 & 2.04 & 2.39 \\
1979 & 2.05 & 2.50 \\
1980 & 1.81 & 2.36 \\
1981 & 1.75 & 2.41 \\
1982 & 1.60 & 2.18 \\
1983 & 1.54 & 2.07 \\
1984 & 1.46 & 1.97 \\
1985 & 1.40 & 1.93 \\
1986 & 1.45 & 1.99 \\
\hline
\end{tabular}

Sources: The projections based on the intermediate-swings model are from the equations of table 5, and those based on the discouraged-worker model are from the equations of table 1 . The assumptions underlying the calculations are described in the text.

baby-boom cohort, with its high participation rates, will be entering the 45-54 age group. The young women of today will be middle-aged and will not be returning to the home. The more difficult question is whether the participation rate for younger women will level off. My assumption is that the more favorable labor-market experience of the baby-bust cohort will lead to an upturn in the fertility rate, and that although the inverse relationship between market work and number of children may weaken somewhat, it will remain strong. The result would then be a substantial slowdown of the growth rate of participation rates from their current high rate of ascent. ${ }^{21}$

Although different specifications of the equations and data sets produce alternative future paths for the participation rates, the two central distinctions remain. Intermediate-swings models always produce lower participation rates for younger workers and higher rates for older workers. On balance, the net effect is a reduction in the anticipated growth rate of the aggregate civilian labor force. These results are shown in table 8. The trend-dominated model projects a continued growth of the labor force of over 2 percent per year for the next ten years. The intermediate-

21. An important short-run, but insignificant factor in the long-run forecasts is that the intermediate-swings variables also reduce the estimate of the pool of discouraged workers. The projections of participation rates of table 7 are derived solely from extrapolating the equation of table 5. No judgmental factors are included, although I would be tempted to alter some of the forecasts. 
swings model, on the other hand, projects a persistent slowdown of growth from 2.04 percent in 1978 to 1.45 percent in 1986.

The caveats that can be added to the story are numerous, but two should be stressed. I assume, first, that government transfer policies will not further affect participation (or reported participation) in the labor force; and, second, that further increases in the immigration rate will not significantly offset the aging of the work force due to the entrance of the baby-bust cohort into the labor market. ${ }^{22}$

\section{Conclusion}

In most previous studies of labor-force participation, the stress has been on short-run fluctuations associated with discouraged workers, with any remaining variation being explained by a trend variable. The thrust of my argument in this paper is that that approach consigns to an unrevealing trend the bulk of the fluctuations in participation rates which can, in fact, be explained systematically by the intermediate-swings and cohort variables. In this context, the central variables become the relative-age structure of the population and total fertility rates. The latter are introduced in lagged form to capture the cohort effect and the conditions prevailing when each age group was in its child-rearing period. Including these variables generally reduces the significance of the discouragedworker effect and the size of the remaining trend component.

The intermediate-swings variables represent a kind of relative-income effect. The influx of the baby-boom generation has significantly depressed the family income of young people relative to desired standards of living, which are based on the income of prime-age men and previous cohorts of young workers. The result has been a decrease in fertility and an increase in labor-force participation among young females in an attempt to maintain desired standards of living. For the youngest workers, school-enrollment rates also dropped as these workers entered the labor market.

A turning point in American economic-demographic history is a few years away. The baby-boom generation will begin to enter the prime-age groups and the baby-bust generation will begin to enter the labor market.

22. This discussion of future trends draws upon Michael L. Wachter and Susan M. Wachter, "The Fiscal Policy Dilemma: Cyclical Swings Dominated By Supply Side Constraints," in T. J. Espenshade and W. I. Serow, eds., The Economic Consequences of Slowing Population Growth (Academic Press, forthcoming). 
I argue that this will lead to three near-term changes in participation behavior. First, as the baby-boom cohort ages, it will raise the participation rates of the older age groups that it enters because of its smaller family size and tradition of high participation rates. Second, the new and smaller cohort of younger workers will enjoy an improving labor market. With less pressure for two wage earners, the participation rate for women may return to a path for the growth rate much lower than that established over the past decade. Third, combining a faster growth rate for older women and a slower growth rate for younger ones with a nearly steady participation rate for prime-age men results in an overall growth rate for the labor force that should fall from over 2 percent per year to approximately 1.5 percent in the early 1980 s.

Given the record, I do not expect the forecasts in tables 7 and 8 to be precise; the variables that I have employed include a mixture of economic and sociological factors that are difficult to quantify with accuracy. My argument is not that the specific forecasts are correct, but that they capture the coming shifts in patterns of participation rates and the growth rate of the labor force. I believe that these changes will occur-and soon; but it is not possible to predict the transition point.

\section{Discussion}

A NUMBER of participants questioned whether participation rates for females would return to their former trends when Wachter's $R P_{y}$ variable does. James Tobin reasoned that the new conceptions about the role of women in society would lead new young cohorts to participate in the labor force at least as intensively as their predecessors. James Duesenberry pointed out that the expanded job opportunities in many occupations formerly closed to women produced an upward ratchet effect in women's participation, regardless of changes in other factors influencing their workleisure decision. In the same connection, Frank Schiff noted the increased availability of part-time work, and Frederic Mishkin stressed the availability of improved birth-control techniques. In response Wachter argued that his equation did not suggest a decline in the participation rate of younger females. Rather, the rate of growth of the participation rate 
would slow dramatically. In the context of the model, the positive timetrend effect outweighed the anticipated decline in $R P_{y}$ and the assumed return of $T F R$ to the 2.1 level.

Charles Holt complimented Wachter on trying to get behind the factors that have led to the observed trend in participation rates. He observed that the poor record of the Bureau of Labor Statistics in forecasting participation indicated the need for research in this area. Holt distinguished three separate effects in the movement of participation rates through time, each of which should be modeled to obtain a full picture of the participation process: first, the effect of changing mores, which would probably have to be captured by a time trend; second, the effect of changes in an individual's age; and third, the cohort effect, which may make people who happen to be born at some one point in time have particular experiences that leave a permanent imprint on their participation behavior. As an example of the third, cohort, effect, Holt mentioned Schweitzer's finding that people's permanent participation rates were affected by the unemployment rate that prevailed when they first entered the labor market. Robert Solow pointed out that the effects Wachter identifies with his timeage variable should, ideally, be disentangled into time, age, and birthdate effects (or into any two, implying the third). This would permit the kind of distinctions Holt described and would provide evidence on whether the results of Wachter's age-time regressions were plausible.

Marina Whitman noted that Wachter's model implied that a high unemployment rate encouraged labor-force participation. Arthur Okun inquired whether Wachter's results should not simply be interpreted as a backward-bending supply curve for labor: the income effects of adversity in the labor market that push the wife into the market outweigh the substitution effects of trading off leisure for labor. Wachter agreed with these comments, but mentioned that the supply curve was only backward bending given aspiration levels. This is different from the static definition of the traditional backward-bending supply curve.

Several participants commented on Wachter's equation specifications. George Perry noted the sensitivity of the results to the particular construction of the $R P_{y}$ variable that was used, and was skeptical about using that variable, which reflected the relative income of the entire 16-34 age group, in explaining the behavior of the several individual age-sex cohorts. Tobin commented that the lagged dependent variable was presumably intended to convey the notion of the persistence in individual 
behavior. But as people get older it is not the same people who appear in a particular age-cohort variable.

Wachter explained that in choosing his specifications he had been severely constrained by lack of certain kinds of data. He argued that the major thrust of his work was to include those cohort effects that could be captured using the available data. To improve on the ability to forecast participation behavior, it is crucial that the Bureau of Labor Statistics provide real cohort data; that is, data for each year by single year of age. He noted that fertility data are already available by age and year. 